\title{
Comentario \\ Los procesos electorales en Centroamérica: notas sobre un estudio de casos
}

Gerardo Monterrosa elegir autoridades edilicias y parlamentarias. En Guatemala, para ser precisos en noviembre del año pasado, se llevaron a cabo comicios generales, resultando electo para la presidencia el militar retirado Otto Pérez Molina. Los nicaragüenses, en medio de un clima de denuncias por parte de la oposición, revalidaron el mandato de Daniel Ortega. En Costa Rica fue investida con la banda presidencial la primera mujer, Laura Chinchilla, como resultado de una cerrada contienda electoral. Finalmente Honduras, luego del golpe de Estado de 2009 y los atropellos que sufre la prensa en estos momentos, tiene en la figura de Porfirio Lobo a su presidente constitucional. Centroamérica, una vez pacificada la región, experimenta los avatares de la transición política, los retos que impone - pese a las críticas y falencias que afronta- la democracia representativa.

Ante este panorama general, la pregunta por la genealogía y desarrollo diacrónico de estos eventos electorales no está de más. Esto, lejos de constituir un interés vano y presuntuoso, resulta una necesidad para comprender los procesos políticos que afrontamos como centroamericanos. La famosa sentencia de Benedetto Croce, "toda historia es historia contemporánea", cobra vigencia ante la interrogante que nos lanzamos por el pasado electoral desde nuestro presente. El tema de la ciudadanía, las agrupaciones políticas durante el siglo XIX y XX y la representación en un sistema político republicano, saltan a un primer plano. No es gratuito que los temas antes mencionados sigan generando polémica, continúen en la agenda mediática y susciten aún acalorados debates. En definitiva, su peso es demasiado fuerte para atrevernos a olvidar su historia. Y esto precisamente es la intención del libro que ahora comentamos.

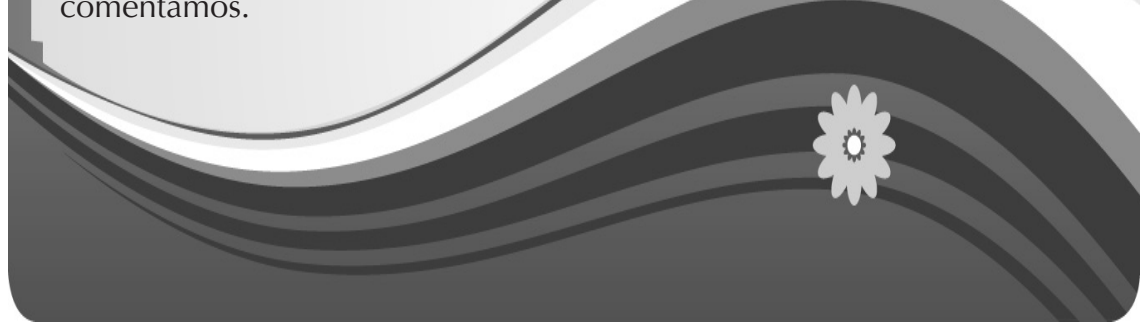


Una vez más los salvadoreños han concurrido a las urnas para elegir autoridades edilicias y parlamentarias. En Guatemala, para ser precisos en noviembre del año pasado, se llevaron a cabo comicios generales, resultando electo para la presidencia el militar retirado Otto Pérez Molina. Los nicaragüenses, en medio de un clima de denuncias por parte de la oposición, revalidaron el mandato de Daniel Ortega. En Costa Rica fue investida con la banda presidencial la primera mujer, Laura Chinchilla, como resultado de una cerrada contienda electoral. Finalmente Honduras, luego del golpe de Estado de 2009 y los atropellos que sufre la prensa en estos momentos, tiene en la figura de Porfirio Lobo a su presidente constitucional. Centroamérica, una vez pacificada la región, experimenta los avatares de la transición política, los retos que impone -pese a las críticas y falencias que afronta- la democracia representativa.

Ante este panorama general, la pregunta por la genealogía y desarrollo diacrónico de estos eventos electorales no está de más. Esto, lejos de constituir un interés vano y presuntuoso, resulta una necesidad para comprender los procesos políticos que afrontamos como centroamericanos. La famosa sentencia de Benedetto Croce, "toda historia es historia contemporánea", cobra vigencia ante la interrogante que nos lanzamos por el pasado electo- ral desde nuestro presente. El tema de la ciudadanía, las agrupaciones políticas durante el siglo XIX y XX y la representación en un sistema político republicano, saltan a un primer plano. No es gratuito que los temas antes mencionados sigan generando polémica, continúen en la agenda mediática y susciten aún acalorados debates. En definitiva, su peso es demasiado fuerte para atrevernos a olvidar su historia. Y esto precisamente es la intención del libro que ahora comentamos.

La pequeña recensión que a continuación desarrollo versa precisamente sobre tres temas específicos: a) la ciudadanía, b) las agrupaciones políticas y c) la representación. Mi intención es trazar ciertas líneas que aborden el contenido del libro, pero también que incentiven ulteriores investigaciones. En procura de este objetivo, me adhiero plenamente a lo escrito por Iván Molina Jiménez, quien reflexiona sobre la Inscripción electoral y asistencia a las urnas en Costa Rica desde 1885 hasta 1913, cuando apunta que "La investigación histórica latinoamericana efectuada en los últimos diez años ha empezado a revalorar el papel jugado por las leyes, instituciones y partidos, y uno de sus aportes principales ha sido demostrar que los factores institucionales, legales y electorales no pueden ser reducidos a simples reflejos de estructuras sociales y económicas" ${ }^{\prime 1}$. 
En la reconstrucción que los historiadores realizan de las diversas etapas políticas centroamericanas, el tema de la ciudadanía ocupa un lugar central. La interrogante que podemos plantear para examinar cada coyuntura es la siguiente: ¿Quiénes podían elegir y ser electos en el terreno de la cosa pública? La respuesta debe sustentarse desde una premisa básica, a saber: los derechos y deberes del ciudadano, lejos de constituir un constructo inherente al ser humano e inmutable, se han construido diacrónicamente. La influencia de las ideologías -que inspiraron la creación y consolidación de nuestros Estados durante el siglo XIX- nos brindan pautas insoslayables para dar cuenta de este proceso. En otras palabras, los derechos políticos que ahora posee un ciudadano tienen una genealogía. La amplitud de estos derechos -hombres y mujeres nacidos en un determinado territorio, mayores de 18 años e inscritos en un padrón electoralno representa una constante en cada época.
Por el contrario, expresa luchas por parte de ciertos grupos, como es el caso de las mujeres que, amparadas en la figura de un caudillo como Somoza García o en pleno cuestionamiento de la cultura política imperante -pienso directamente en la postura sostenida por Prudencia Ayala en 1930-, reclamaron una participación activa en la palestra pública² ${ }^{2}$. Pero también representa un tema importantísimo para aquellos que ocupan el poder político, es decir, el de la legitimidad de su mandato.

La ampliación de la categoría de ciudadano -que en este libro podemos examinar- repercute directamente en el ámbito electoral. Desde el siglo XIX hasta el siglo XX podemos hablar de un tránsito muy importante que responde a las diferentes exigencias coyunturales, es decir, a los equilibrios políticos que resultan necesarios preservar $y$ la legitimidad que desearon imprimir los regímenes de turno. Un relato de un agricultor herediano, en la víspera de los comicios de 1859 en Costa Rica, ilustra la restricción de la ciudadanía que existió en la región:

"...la Junta Calificadora -afirmó éste- de mi vecindario, me ha inferido el notorio agravio de no inscribirme en la lista de ciudadanos calificados... sin escuchar la voz de la justicia ni el eco de la razón, por lo que me veo en la imperiosa necesidad de alzarme de aquella providencia... La única razón que ha tenido la honorable Junta para negarme mi goce de ciudadano es la de asegurar que no soy dueño de una propiedad raíz que llegue al valor de trescientos pesos..."3 
Del voto censitario y cualificado -que imperó sobre todo en el siglo XIX-se pasó a mediados del siglo XX en nuestra región -Guatemala, 1945; Costa Rica, 1949; El Salvador, 1950; Honduras, 1955; y Nicaragua, 1955- a la inclusión de un importante sector de la población marginado desde la fundación de nuestras Repúblicas, es decir, la mujer. En el caso salvadoreño fue específicamente durante la Ad- ministración del teniente coronel Óscar Osorio -el primer mandatario del Partido Revolucionario Institucional (PRUD)- cuando la mujer obtuvo el derecho de emitir el sufragio. Veinte años transcurrieron para que las palabras de Prudencia Ayala, al retirarse de la contienda política de 1931 -ante la prohibición que estipuló la Corte Suprema de Justicia- alcanzaran concreción:

Me alejo almas mías con el corazón satisfecho de haber entrado en combate para obtener el triunfo de mi derecho ciudadano. Me alejo con grata de los políticos que han prestado atención a la justicia que reclamo en el campo de la ley. La patria exige la práctica de la justicia, el cumplimiento de la ley en su más completo significado cívico social entre hombre y mujeres, para equilibrar los valores morales de la nación civilizada. Así la alegría embarga mi esperanza en el próximo futuro electoral${ }^{4}$.

El tema de la ciudadanía, vinculado estrechamente a los procesos electorales, engarza con el de la representación, es decir, los mecanismos utilizados para seleccionar a los ciudadanos encargados de velar -en teoría- por el funcionamiento de las instituciones del Estado y el bienestar común. Ricardo Dardón Flores, quien reflexiona sobre el "voto y representación política en la patria del criollo: la primera experiencia constitucional en Guatemala", afirma que uno de los bastiones de la Modernidad política, implementada por las Cortes de Cádiz para salvar la cohesión de la Monarquía, fue precisamente "El voto para delegar en otros un poder que pertenece a todos: la soberanía". Según Dardón:

El desenvolvimiento político de España y sus colonias muestra el desarrollo de la modernidad política de la Ilustración. Evidencian lo anterior el surgimiento de constituciones; la novedad de la soberanía en el pueblo, como principio de legitimidad; la transferencia, a través del voto, de la soberanía del pueblo a representantes locales, diputados, etc.; la aparición de hombres y grupos especializados en 
la acción política; el uso de un lenguaje político abstracto (pueblo, soberano, ciudadano, vecino, etc.); el proceso de elecciones y otras más 5 .

Durante el siglo antepasado estos preceptos fueron desarrollados en nuestro continente. "Un dato significativo, como lo explica Hilda Sábato, caracteriza la historia política de las Américas en el siglo XIX: la adopción generalizada de formas republicanas de gobierno. Mientras Europa abrazaba la monarquía con renovados bríos, las Américas, con la sola excepción sostenida del Brasil, optaron definitivamente por la república. De esta manera se convirtieron en un campo de experimentación formidable" ${ }^{\prime 6}$.

Bajo este esquema $-y$ necesitando estudios que inspeccionen los mecanismos de representación durante el siglo XIX-, arribamos a la centuria que recién dejamos atrás. En el caso salvadoreño, desde diciembre de 1931 cuando los regímenes militares se instauraron en el poder, la representación territorial constituyó la herramienta para elegir a los diputados del Salón Azul. El partido político que obtenía la mayoría de votos en un departamento se adjudicaba todos los curules disponibles en dicha circunscripción. Pese a los reclamos de la oposición, que se expresaron de forma vehemente durante la década de los cincuenta -presidida políticamente por el PRUD- el mecanismo de representación no fue alterado y, por lo tanto, el unipartidismo en la Asamblea Legislativa benefició directamente los intereses oficialistas.

Fue en 1962, ante un período de convulsión política donde las Fuerzas Armadas ratificaron su posicionamiento en la política nacional, que la representación proporcional fue anunciada. En el discurso de toma de posesión -el primero de julio de 1962- el coronel Julio Rivera lanzó un Ilamado a los partidos políticos:

Lo único que solicitamos a quienes no compartieron nuestras ideas en la pasada confrontación electoral, es que sepan juzgar correctamente nuestro propósito de conciliación nacional; que acepten como única definición legítima el dictado de la soberana voluntad popular, y que, como contingente cívicos evolucionados y cultos, no nieguen su concurso de inteligencia, patriotismo y honradez a las altas responsabilidades que el pueblo salvadoreño, deseoso de paz y de progreso, nos señala a todos por igual, sin discriminaciones ni reservas, como ciudadanos capaces de en- 
tender que El Salvador está por encima de cualquier interés personal deleznable. ${ }^{7}$

Una estrategia de apertura política estaba en los planes del nuevo gobierno. Retomando el discurso inaugural de su quinquenio encon- tramos el anunció de una medida política que -según la perspectiva de Rivera- coadyuvaría a enaltecer los intereses de la nación:

\begin{abstract}
A los partidos políticos corresponde, en este sentido, la obligación patriótica ineludible de reconocer que su verdadera misión está en aglutinarse, no en torno a los individuos, sino a los principios, e inspirarse, no en los apetitos de un grupo, una clase social o una fuerza privilegiada, sino en los reclamos del interés supremo de la Nación. Consecuente con el espíritu de estas ideas, una de las mayores preocupaciones de nuestro gobierno será el estudio de una ley adecuada y práctica que confiera al Cuerpo Electoral el derecho de la representación proporcional en el órgano legislativo ${ }^{8}$.
\end{abstract}

Y en efecto, el 11 de enero de 1963 Julio Rivera envió una excitativa al Concejo Central de Elecciones (CCE) para elaborar un ante-proyecto que sustituyera la representación geográfica. El gran objetivo de esta reforma no era otro que instaurar la representación proporcional. Así, la solicitud de los partidos de oposición -hecha con anterioridad- encontraba concreción. Empero, resulta clave señalar que el Consejo Consultivo Pre-electoral -instaurado en 1961ya había propuesto esta medida. Sin embargo, esta solicitud no fue adoptada para las elecciones a la Constituyente, sino hasta 1963, es decir, cuando Julio Rivera cumplía su segundo año en la silla presidencial. En síntesis, las quejas del PDC ante la negligencia del Directorio Cívico Militar alcanzaron eco con la entrada en vigencia de la representación proporcional. No obstante, la Asamblea Legislativa hizo posible que Rivera se llevara los créditos.

La estrategia del gobierno militar fue la de abrir espacios políticos a una oposición cada vez más beligerante. Esta apertura permitió al PDC, fundado en noviembre de 1960, acumular un fuerte apoyo electoral durante esta década y retar -doce años más tarde mediante la conformación de la Unión Nacional Opositora (UNO) - la permanencia de los militares en el Ejecutivo. Sin embargo, en 1972 el carácter restrictivo de esta apertura hacia la oposición legalizada se hizo presente. La imposición, el fraude y el exilio de José Napoleón Duarte, ante el apoyo que éste brindó al 
fallido golpe de Estado perpetrado en marzo de ese mismo año, le permitieron al PCN mantener el poder.

El caso salvadoreño nos introduce a nuestro último tema: el de las agrupaciones o partidos políticos. Desde el siglo XIX los clubes con personas dedicadas a la tarea proselitista invadieron el escenario político de nuestra región. Para seleccionar a los diputados que representarían a Centroamérica en las Cortes de Cádiz, el Congreso del Imperio del Septentrión y ante la máxima entidad de la Federación, las facciones jugaron un papel preponderante $^{9}$. Fue en su seno, mediante los debates que podemos seguir en los periódicos de la época, que se ejerció el derecho a la participación política. Las pugnas que generó la exigencia de ciertos grupos por construir un Estado laico, nos permiten observar -lejos de toda clasificación maniquea entre liberales y conservadores- la variedad ideológica que imperaba en estos clubes $^{10}$. El tema de fondo -a diferencia de México con el Segundo Imperio- era el papel que debía jugar la Iglesia en el sistema republicano y cuál era la mejor forma de estructurar la administración pública. Por lo tanto, reducir este conflicto a dos bandos homogéneos representa una pérdida ingente de la riqueza política de la época.

Ya en el siglo XX encontramos el interesante renglón de los partidos políticos. Todavía se discuten las continuidades y discontinuidades entre éstos y sus antecesores decimonónicos. Sin embargo, más allá de este debate, -muy rico para plantear las características de cada uno- podemos afirmar que la amplitud de la categoría de ciudadano -con respecto a sus derechos políticos- forzó a los partidos del siglo XX -paulatinamente por supuesto- a convertirse en un fenómeno de masas.

Desde la aurora de los partidos políticos en Guatemala (19441954), donde los regímenes de turno abrieron el espectro de la participación partidaria ${ }^{11}$, hasta las proscripciones de agrupaciones políticas realizadas en El Salvador (1950) y Costa Rica (1953), el tema de la legalidad de ciertas ideologías partidarias configuró el escenario centroamericano. Sobre todo, cuando evaluamos esta coyuntura a la luz del ambiente de guerra fría. Sin duda alguna $-y$ hablo sobre todo del caso salvadoreño- un estudio pormenorizado de los partidos políticos, sus agendas programáticas, el desenvolvimiento que tuvieron en los comicios y las figuras que los impulsaron, está pendiente en la agenda académica. Esperemos que este libro colabore a despertar el interés por nuestra historia política. Que los temas de ciudadanía, representación y partidos políticos se relacionen adecuadamente para mostrarnos el camino recorrido, ese que nos constituye y permite lanzar un vistazo desde el presente hacia el pasado. 
y el mundo, tiempos históricos, Madrid: Marcial Pons Editores, 2006, p. 263.

7 Dirección General de Publicaciones, "Mensaje del Coronel Julio Adalberto Rivera al pueblo salvadoreño al tomar posesión de la Presidencia de la República”, en AGN de El Salvador. p. 31.

8 Ibid., p.31. Subrayado en el original.

9 Xiomara Avendaño, "El imperio del Septentrión: elecciones para elegir diputados al primer congreso constituyente mexicano”. Pp. 53-101.

10 Sajid Herrera, “¿Liberales contra Conservadores? Las facciones políticas en El Salvador del siglo XIX", Pp. 177215.

11 Guadalupe Rodríguez de Ita, "La aurora de los partidos políticos en Guatemala, 1944-1954", Pp. 217-258. 